\title{
Numerical Analysis of Ground Motion Effects in the Loess Regions of Western China
}

\author{
Tuo Chen, ${ }^{1}$ Wei Ma, ${ }^{2}$ and Jianzhou Wang ${ }^{1}$ \\ ${ }^{1}$ The State Key Laboratory for Geomechanics and Deep Underground Engineering, China University of Mining \& Technology, \\ Xuzhou 221116, China \\ ${ }^{2}$ State Key Laboratory of Frozen Soil Engineering, Northwest Institute of Eco-Environment and Resources, CAS, \\ Lanzhou 730000, China \\ Correspondence should be addressed to Wei Ma; mawei@lzb.ac.cn
}

Received 18 January 2017; Accepted 9 July 2017; Published 14 September 2017

Academic Editor: Salvatore Russo

Copyright $@ 2017$ Tuo Chen et al. This is an open access article distributed under the Creative Commons Attribution License, which permits unrestricted use, distribution, and reproduction in any medium, provided the original work is properly cited.

Loess is widely distributed in the western part of China and its area comprises $6.6 \%$ of Chinese territory. Because of the characteristics of high porosity, low strength, and weak cementation, the loess is characterized by high seismic vulnerability which has been observed and confirmed by many researchers at home and abroad. The postquake field investigation and the laboratory study have shown that the ground motion effects, including the amplification effects and slope effects, were obvious in loess sites. Moreover, the causes of landslides, seismic subsidence, and liquefaction were mainly attributed to this special soil structure and properties. In this paper, based on the data of shear wave velocity of typical loess in Lanzhou region, combining the results of dynamic triaxial tests, the numerical analysis of ground motion effects in the loess regions is analyzed. The results reveal how the ground motion effects are checked and demonstrated the important role of numerical simulations while studying the characteristics of ground motions.

\section{Introduction}

The loess is one kind of typical structural soil and is with an area of $630,000 \mathrm{~km}^{2}$ which comprises $6.6 \%$ of Chinese territory [1]. Because of the special structure characteristic, the mechanics and engineering properties are determined. The loess has the seismic vulnerability which means that the microstructure and the mechanical properties of loess will make adaptive changes under the strong vibration and which can affect the macroscopic strength and deformation characteristics, even leading to instability and failure [2]. The loess plateau area of China is the place where loess has most extensive distribution, the largest thickness, and a great diversity of types [3]. In addition, the loess plateau is one of the most tectonically active areas of the world and also one of the most seismically active regions. There were 367 earthquakes with magnitude greater than Ms5.0 occurring in this region, among which 7 events are with magnitude equal to or greater than Ms8.0, 20 events are with magnitude within Ms7.0-7.9, and 71 events are with magnitude within Ms6.0-6.9 [4]. The postquake field investigation has shown that the ground motion effects in loess sites during the 2008 Wenchuan Ms8.0 earthquake [5] and the 2013 MinxianZhangxian Ms 6.6 earthquake [6] were obvious which aggravated the earthquake disasters. These earthquakes caused seriously damage and most severe disasters in the vast loess region, like landslide, debris flow, soil liquefaction, and so forth. Therefore, it was very important and pressing to study earthquake disaster mitigation and prevention in the loess regions of western China.

The study of the ground motion effect in loess areas is an issue of growing interest in recent years. In consequence, many resources have been invested to understand these phenomena, especially the mechanism of seismic ground motion. Firstly, the seismic data was recorded in order to estimate the site effects. Authors such as Cruz et al. [7] 
used data from low intensity events which occurred in 1989 and 1990 to make a preliminary evaluation of site amplification effects. The site amplification characteristics had been identified by Kumar et al. [8] from the frequency bands of significant amplification observed in the spectral ratios of the horizontal to the vertical component records. Furthermore, Hassani et al. [9] used the generalized inversion of the S-wave amplitude spectra from the strong-motion network data in East-Central Iran to estimate simultaneously source parameters, site response, and the S-wave attenuation. Qadri et al. [10] analyzed the site response at 13 different sites within urban settlements of Fateh Jang area, applying the H/V spectral ratio method. In loess areas of China, the ground motion effects were observed after earthquakes which attracted the attention of some researchers. There are some examples in the literature, such as Shi et al. [11], who proposed an experiential method of evaluating effects of overburden thickness and topography on ground motion based on a lot of statistical data of seismic response of sites. Moreover, Numerical Methods are used to assess the site effects. Based on the earthquake damage investigation after Wenchuan Ms8.0 earthquake, site seismic response analysis of the typical loess tableland was conducted by Wu et al. [12]. Chen et al. [13] studied the effects of site conditions on earthquake ground motion in loess sites applying the dynamic finite element analysis method and pointed out that the magnification is related to the loess thickness and slope grades, which is in accordance with the earthquake damage observation. On the whole, there are not many related studies about the ground motion effects in the loess regions of western China. Although some conclusions are drawn after qualitative analysis and calculation, the quantitative assessment of ground motion effects should be further investigated.

In this study, the data of shear wave velocity of typical loess in the loess regions of western China are collected, and the results of dynamic triaxial test are studied as well. On the basis of the above analysis, numerical analysis of ground motion effects in the loess regions, mainly including two parts, is conducted. The first part is the amplification effect of the loess site, and the seismic responses calculation is carried out applying the equivalent linear method. The second part is seismic response of slope, the FEM model of typical slope was developed, and subsequently the dynamic finite element analysis is conducted. The results of this research will be of interest for researchers and civil engineers and provide some guidance for the resisting earthquake and preventing disasters in loess areas of China.

\section{Shear Wave Velocities and Kinetic Parameters of Loess}

2.1. Shear Wave Velocities of Loess. Dynamic soil stiffness, as indicated by either shear modulus or shear wave velocity, is a prerequisite parameter for dynamic analysis of site seismic response. In this paper, the shear wave velocity structure in loess regions is analyzed based on the statistical velocity data.

Different types of rocks and soils have different elastic wave propagation features, which influence the dynamic response of the sites. In an infinite elastic medium, the shear wave velocity $V_{S}$ and the compression wave velocity $V_{P}$ can be confirmed by applying the following formula:

$$
\begin{aligned}
& V_{P}=\sqrt{\frac{E(1-\mu)}{\rho(1+\mu)(1-2 \mu)}}, \\
& V_{S}=\sqrt{\frac{E}{2 \rho(1+\mu)}}=\sqrt{\frac{G}{\rho}} .
\end{aligned}
$$

In the formula mentioned above (see (1)), $E$ is Young's modulus, $G$ is shear modulus, $\rho$ is the density, and $\mu$ refers to Poisson's ratio. It is indicated that the soil with high $V_{S}$ is regarded to have a greater shear modulus.

For the loess, the wave velocity characteristics vary in different regions. The wave velocity, especially the shear wave velocity, influencing the ground effect in the loess regions, becomes one of the key parameters in calculating. In this paper, the typical loess plateau region in Lanzhou city is selected as the research object and the wave velocity data in this regions are collected. According to the statistical data provided by Shi et al. [14], $V_{S}$ of typical loess varies from $110 \mathrm{~m} / \mathrm{s}$ to $310 \mathrm{~m} / \mathrm{s}$ and the average value is $220 \mathrm{~m} / \mathrm{s}$, while $V_{P}$ varies from $195 \mathrm{~m} / \mathrm{s}$ to $346 \mathrm{~m} / \mathrm{s}$ and the average value is $297 \mathrm{~m} / \mathrm{s}$. Owing to the correlation between the ground motion parameters and $V_{S}$, the elementary variation law of $V_{S}$ with the increase of the soil layer depth is obtained as well. Based on the quantitative analysis of the 54-sample test data, this relationship can be expressed as the simple linear regression model listed below:

$$
V_{S}=73+21 H .
$$

In this formula (see (2)), $H$ refers to the depth and $R$-square is 0.874 when $H$ is less than $20 \mathrm{~m}$. The data of $V_{S}$ should be used in the following numerical calculation.

2.2. Kinetic Parameters of Loess. The kinetic parameters of loess, including the shear modulus and damping ratios, are changing under the different shear strain amplitude. The shear moduli, damping ratios, were determined by dynamic triaxial tests conducted by the Key Laboratory of Loess Earthquake Engineering, China Earthquake Administration. The kinetic parameters of typical Lanzhou loess are shown in Table 1 . The dynamic shear modulus ratio $G / G_{0}$ of Lanzhou loess decreases with the increase of the shear strain, while the damping ratios $\lambda$ increases with the shear strain increasing.

\section{Input Seismic Motions}

Artificially synthesizing or simulating seismic ground motion that satisfies some prescribed engineering properties, that is, generating artificial ground motion or design ground motion, is an important issue in earthquake engineering. The engineering properties of ground motion include three main aspects, that is, the amplitude, the spectrum, and the duration. One of the basic topics related to the generation of artificial ground motion is synthesizing the acceleration time history compatible with given target response spectrum, that 


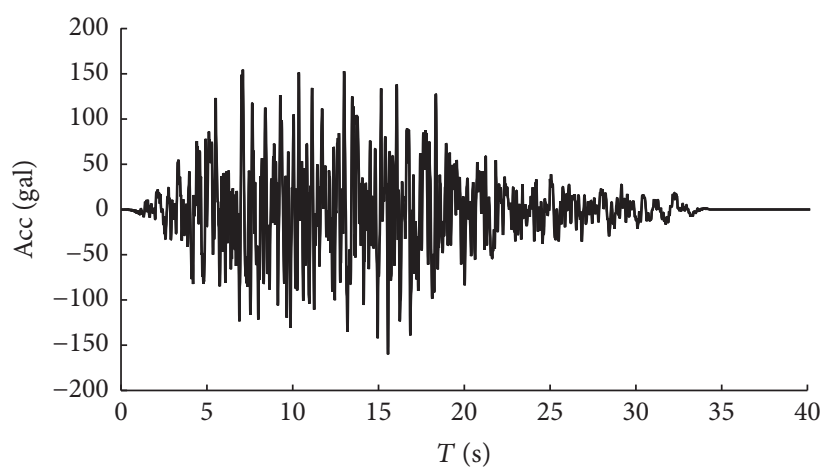

(a)

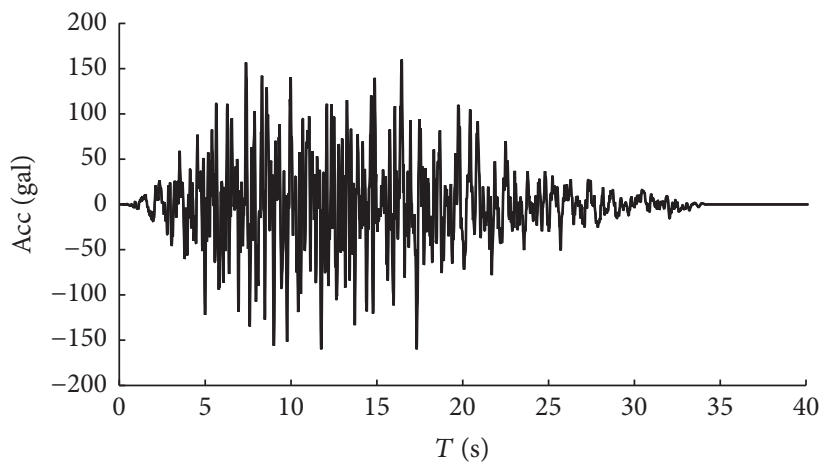

(b)

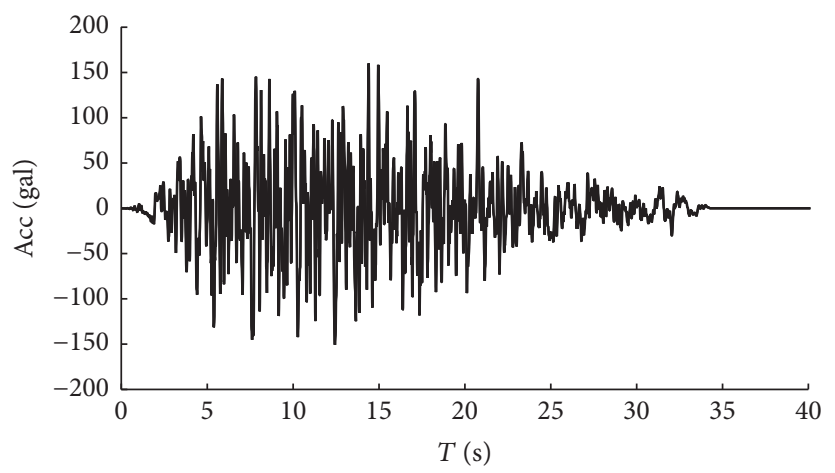

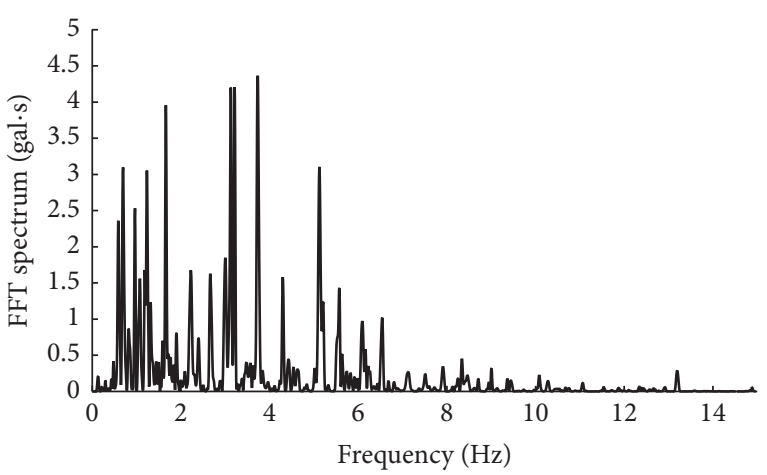
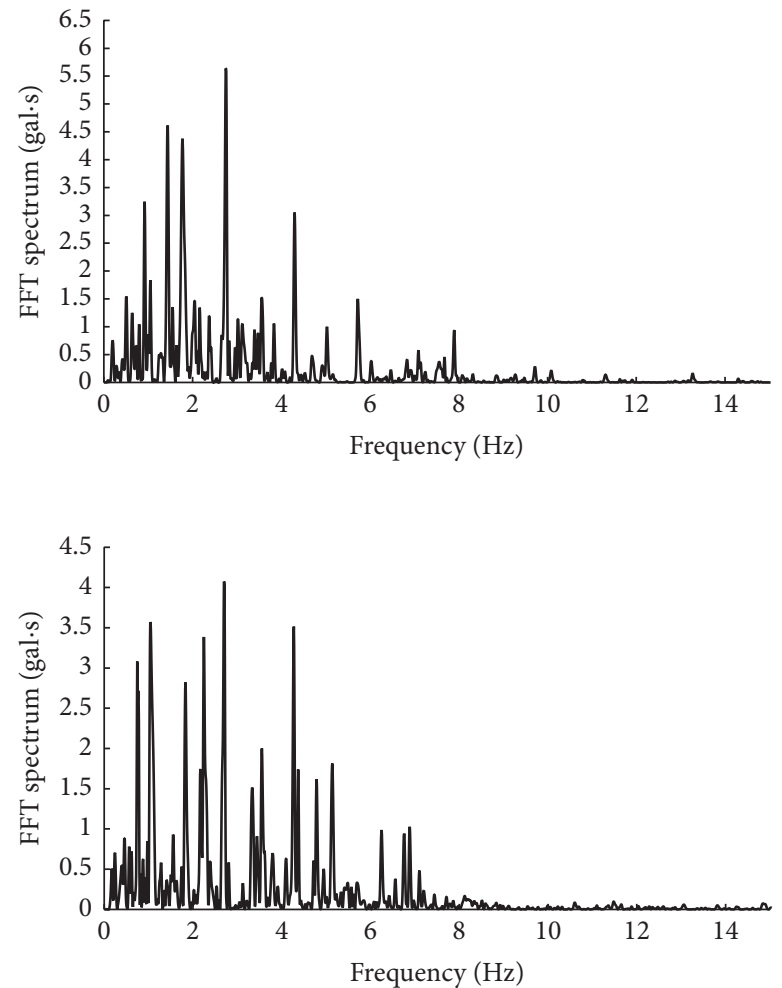

(c)

Figure 1: The artificial seismic waves with exceedance probabilities of $10 \%$ in 50 years: (a) schedule 1 of the seismic waves; (b) schedule 2 of the seismic waves; (c) schedule 3 of the seismic waves.

is, fitting artificial ground motion with the target response spectrum.

In this paper, the Lanzhou loess sites are selected as the study area, and the intensity of seismic ground motion, history of earthquake damage, and site conditions are considered as well. Based on the method that takes the power spectrum and the enveloping curve as double target functions [15], the artificial seismic waves with exceedance probabilities $62.5 \%, 10.0 \%$, and $2.0 \%$, respectively, in 50 years, were synthesized consequently. The maximum amplitudes of the seismic motions were $47 \mathrm{~cm} \cdot \mathrm{s}^{-2}, 160 \mathrm{~cm} \cdot \mathrm{s}^{-2}$, and $300 \mathrm{~cm} \cdot \mathrm{s}^{-2}$, respectively. In this paper, the seismic ground motion analysis is conducted under the seismic loading with exceedance probabilities of $10.0 \%$. The earthquake acceleration time histories and the spectral characteristics of the artificial seismic waves with exceedance probabilities of $10.0 \%$ in 50 years are shown Figure 1. The predominant frequency of the artificial seismic waves is about $3 \mathrm{~Hz}$. In order to decrease the influence of random phase, three time history curves are used as the input seismic motion.

\section{The Seismic Ground Motion Analysis}

Ground motion acceleration and response spectra of the loess regions were determined by site response analyses. Site response analysis can be performed in one-dimensional (1D), two-dimensional (2D), or three-dimensional (3D) wave 
TABLE 1: The kinetic parameters of typical Lanzhou loess.

\begin{tabular}{lccccccrr}
\hline Index & \multicolumn{9}{c}{ Shear strain $\left(\times 10^{-4}\right)$} & 5 & 10 & 50 \\
\hline$G / G_{0}$ & 0.05 & 0.1 & 0.5 & 1 & 5 & 0.288 & 0.110 \\
$\lambda$ & 0.965 & 0.914 & 0.885 & 0.750 & 0.634 & 0.055 \\
\hline
\end{tabular}

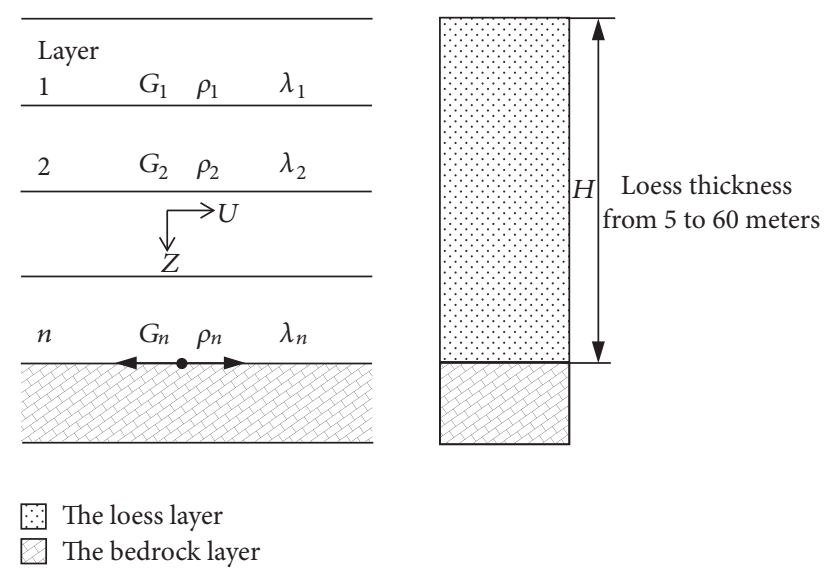

Figure 2: The two-layer calculation model.

propagation analysis. $2 \mathrm{D}$ or $3 \mathrm{D}$ analysis is capable of modeling the effects of relatively complex basin geometry or topography. In this paper, the one-dimensional (1D) equivalent linear method is used for numerical analysis of ground motion effects in the loess regions [16].

$1 \mathrm{D}$ wave propagation analysis is based on the assumption that the response of soil deposits is predominantly caused by the vertical propagation of shear wave from the bedrock. Each layer is assumed to be homogenous and isotropic and is characterized by the shear modulus, soil density, damping ratio, and thickness. The vertical propagation of shear wave motion through the system can be calculated based on the solution to the wave equation. The characteristic of this method is that the definite calculating parameters, as the equivalent shear modulus and damping ratios, are used to describe the complex changes of the soil. Then the iterative method is applied for dynamic response calculation, and thus the nonlinear problem is changed into a linear problem.

4.1. Numerical Computing Scheme. The purpose of this study is to obtain the characteristics of the seismic ground motion, based on which the numerical computing scheme is applied (Figure 2). As shown in Figure 2, the two-layer calculation model contains the upper loess layer and the bottom bedrock layer, and the thickness of the upper loess layer is set to be a variable quantity $H$ which ranges from 5 to 60 meters, while the thickness of the bottom bedrock layer is invariant as well. The loess material is modeled by single layer, and $V_{S}$ of the loess layer is defined from (2) by using thickness of loess layer. Then the dynamic calculation is carried out with different loess thickness applying the $1 \mathrm{D}$ equivalent linear method.
4.2. Analysis of Response Spectra for Acceleration. The acceleration spectra under seismic ground motion with exceedance probabilities of $10 \%$ in 50 years, including the three schedules of artificial seismic waves, were shown in Figure 3. It can be seen that the response spectrum of the sites with different loess thickness has approximately the same shape, except for some difference in the short period. The response spectra have the obvious tendency toward the direction of longperiod segment, with the increase of the loess thickness. Moreover, the peak acceleration response spectrum is gradually increasing with the increase of the loess thickness as well.

4.3. Analysis of Peak Ground Acceleration. The peak ground acceleration of the loess sites with different thickness under seismic ground motion, with exceedance probabilities of $10 \%$ in 50 years, is studied in this paper. In order to quantify the amplification effect of the loess site, the amplification coefficient which is the ratio of peak ground acceleration (PGA) to input seismic acceleration is introduced in this paper. The distribution of the PGA amplification coefficients is shown in Figure 4. The dynamic response of the sites with different loess thickness reflects obvious amplification effects. As the soil layer thickness increases, the amplification coefficients have nonlinear increase, and the average coefficient increases first and then decreases. The minimum value of the average coefficient reaches 2.0, while the maximum value reaches 2.8 . Then the nonlinear characteristics of the amplification effect in loess sites, under the seismic ground motion, could be observed as well.

4.4. Analysis of Maximum Shear Strain. The maximum shear strains under seismic ground motion with exceedance probabilities of $10 \%$ in 50 years, including the three schedules of artificial seismic waves, were shown in Figure 5. It is concluded that the maximum shear strains of the loess sites first increase and then decrease with the increase of the soil layer thickness, which is analogous to the distribution of the PGA amplification coefficients. The minimum value of the average shear strain reaches $2.4 E^{-4}$, while the maximum value reaches $3.4 E^{-4}$ when the thickness of the overburden in loess region is about $35 \mathrm{~m}$.

4.5. Analysis of Spectra's Characteristic Periods. The characteristic period is an important engineering parameter of acceleration response spectrum reflecting the characteristics of seismic motion and the site property.

The distribution of the characteristic periods is shown in Figure 6. It can be found that the characteristic period of the seismic response spectrum gradually increases with 

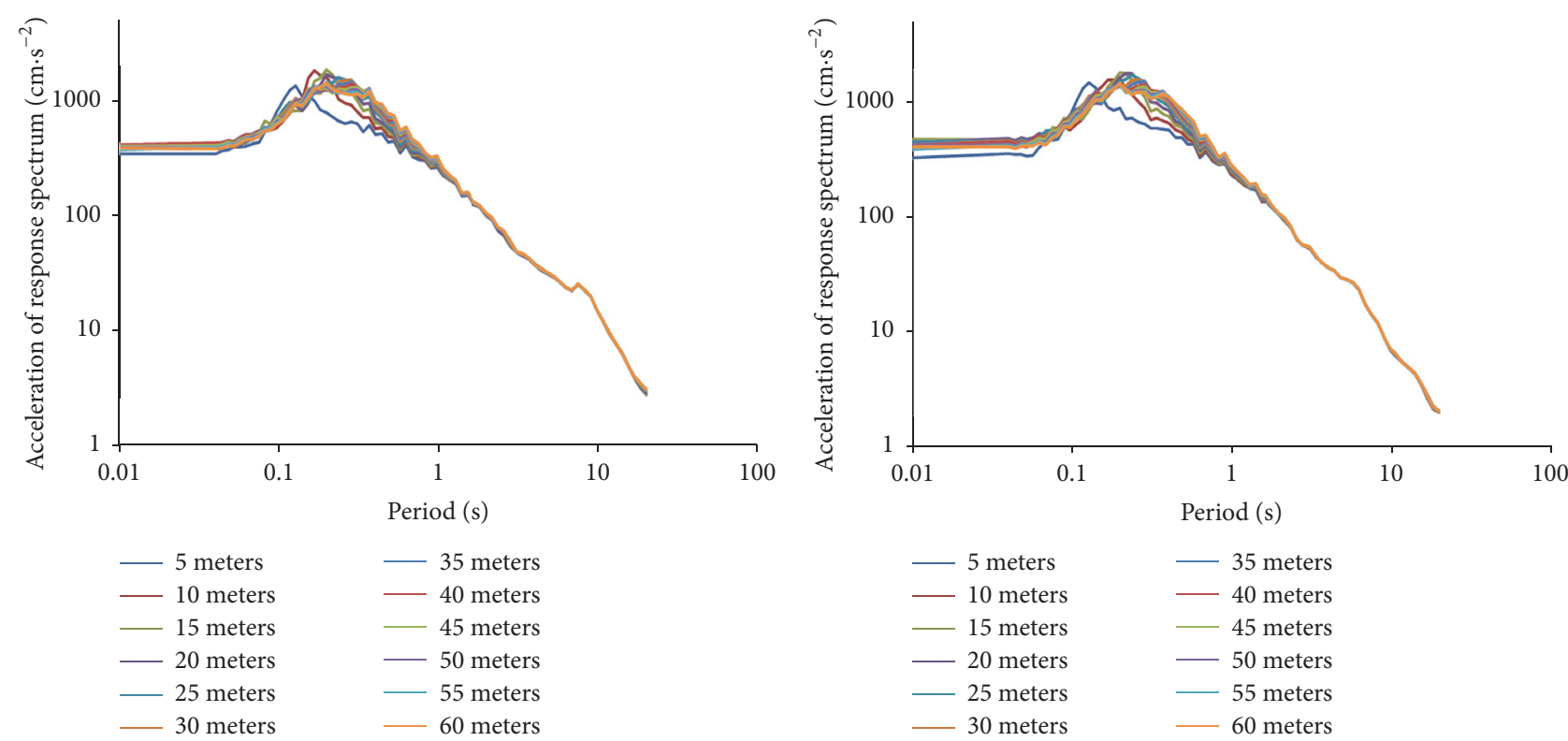

(a)

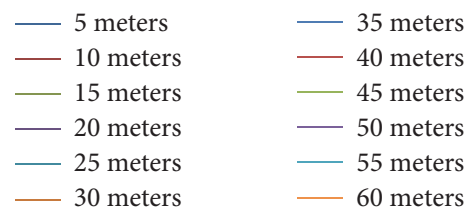

(b)

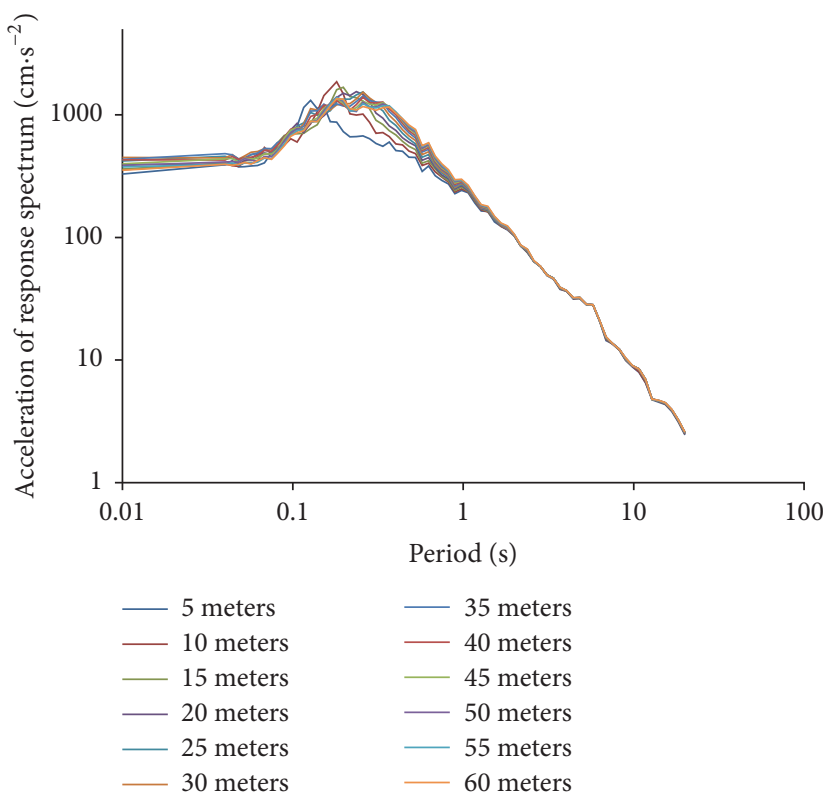

(c)

FIGURE 3: Acceleration spectra under seismic ground motion with exceedance probabilities of $10 \%$ in 50 years: (a) schedule 1 of the seismic waves; (b) schedule 2 of the seismic waves; (c) schedule 3 of the seismic waves.

the increase of the soil layer depth, while the growth rate decreases with the increasing overburden thickness. The variation law of the characteristic periods with the loess thickness, presenting the logarithmic variation characteristics, can be fitted by (3), and the $R$-square is 0.9935 .

$$
y=0.1005 \ln (x)+0.052
$$

In the formula mentioned above (see (3)), $x$ is the loess thickness, and $y$ refers to the characteristic period.

\section{The Study of Slope Effect with Finite Element Method}

5.1. Numerical Model and Mechanical Parameters. Through the above analysis and discussion, the amplification effects of soil sites on ground motions are presented. And, on this basis, the influences of the loess slope on the amplification effects of the seismic ground motion are studied as well. The two-dimensional (2D) finite element analysis model of the typical loess slope is built according to the numerical computing scheme mentioned above. In order to correspond 
TABLE 2: Soil mechanics parameters of the finite element model.

\begin{tabular}{lcccccc}
\hline Lithology & $\begin{array}{c}\text { Thickness } \\
(\mathrm{m})\end{array}$ & $\begin{array}{c}\text { Density } \\
\left(\mathrm{kN} \cdot \mathrm{m}^{-3}\right)\end{array}$ & $\begin{array}{c}\text { Elasticity modulus } \\
(\mathrm{MPa})\end{array}$ & $\begin{array}{c}\text { Poisson ratio } \\
\text { Cohesion } \\
(\mathrm{kPa})\end{array}$ & $\begin{array}{c}\text { Frictional angle } \\
\left({ }^{\circ}\right)\end{array}$ \\
\hline Loess & 60 & $16 \sim 19$ & $140 \sim 350$ & 0.35 & $32 \sim 46$ & 18 \\
Bedrock & 10 & 23 & 1200 & 0.2 & 120 & 34 \\
\hline
\end{tabular}

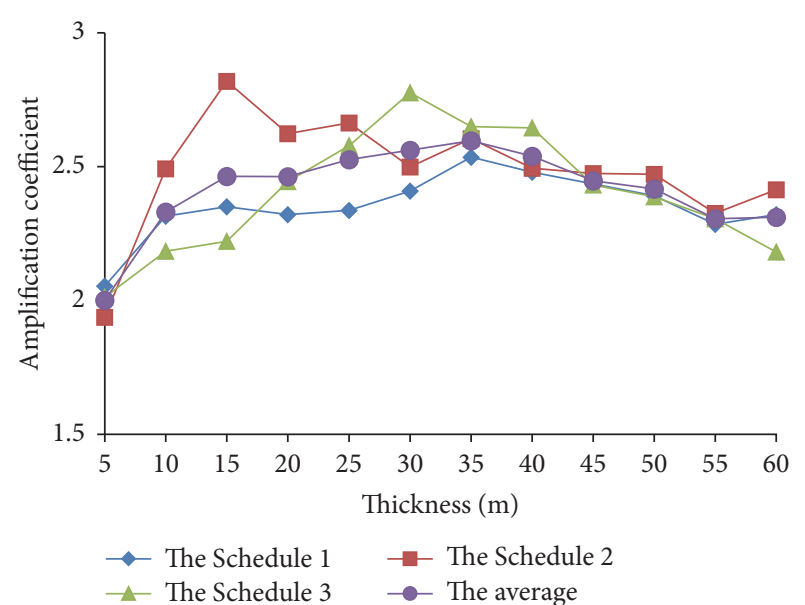

FIGURE 4: The distribution of the PGA amplification coefficient.

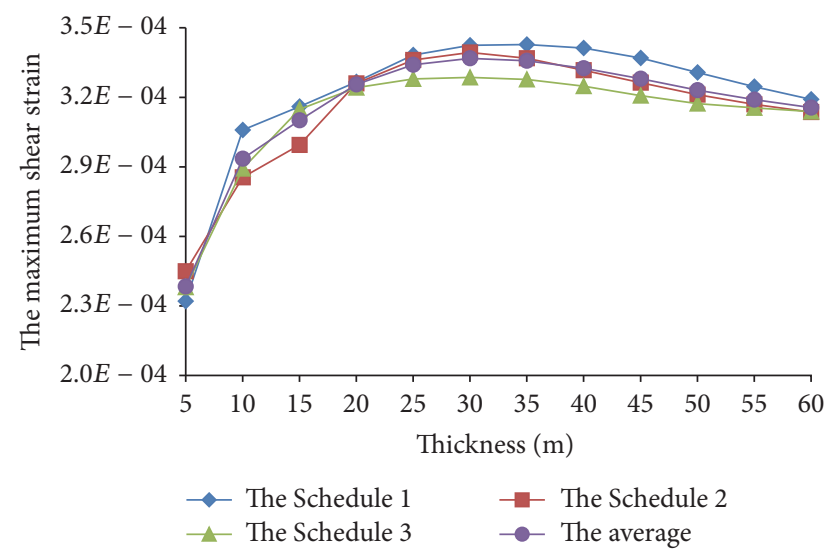

FIGURE 5: The distribution of the maximum shear strains.

to the above $1 \mathrm{D}$ calculation, the two-layer calculation model contains the upper loess layer and the bottom bedrock layer which are considered. The loess material is modeled by single layer, which contains 12 layers, and the thickness of each layer was set as 5 meters. The different densities and mechanical parameters, agreeing with the above $1 \mathrm{D}$ calculation, were endowed as well.

The analysis model of the loess slope was shown in Figure 7; the slope angle of the finite element model was set as 45 degrees. The element of the model was set as the plane strain element. Moreover, in order to decrease the effect of boundary conditions on train vibration, the model combined finite element and infinite element methodology, in which the bottom boundary was fixed and the two side boundaries were set as infinite elements. In view of the research purposes and

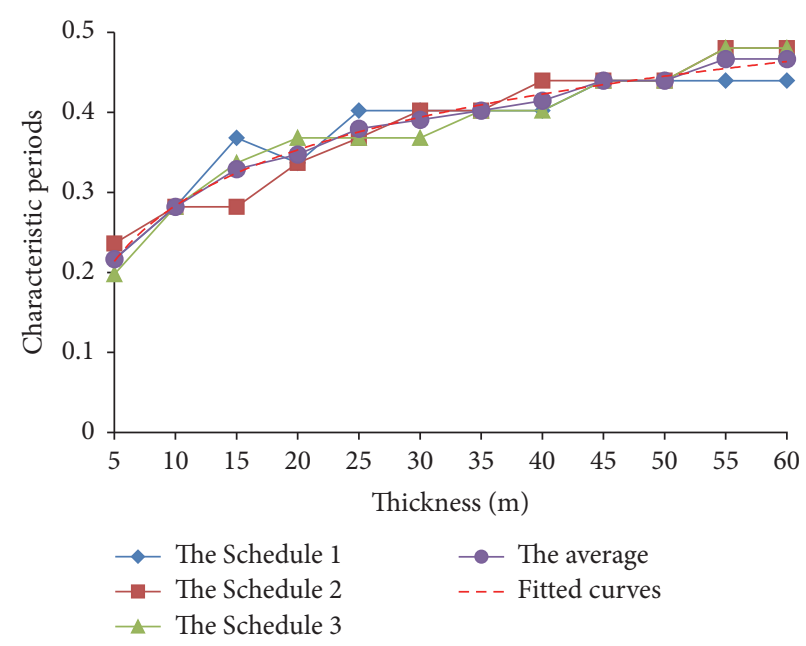

FIgURE 6: The distribution of the characteristic periods.

significance, one monitoring profile $\mathrm{AB}$, along the free face of loess slope and twelve observation points from $\mathrm{C}$ to $\mathrm{D}$, was arranged in the model.

Before dynamic calculation, we used the $1 \mathrm{D}$ equivalent linear method to calculate the dynamic response characteristics of free field soil. And then the soil values of dynamic shear modulus and damping ratio were finally decided while the maximum shear strain occurred. In our 2D finite element dynamic analysis, the soil was regarded as an elastic-plastic material and the elasticity modulus is decided according to the wave velocity mentioned above. Moreover, the MohrCoulomb yield criterion was adopted as well [17], and the soil mechanical parameters for finite element numerical calculation which are shown in Table 2 were obtained by triaxial tests [18].

5.2. The Amplification Effect on Loess Slope. It is discovered long ago that the slope effect of seismic acceleration exists under the seismic actions, which means the slopes have the amplification effect on the acceleration and cause more severe earthquake damage. In this paper, the slope effect is studied by using the plane strain FEM, and the seismic loading uses one schedule of earthquake acceleration time histories mentioned above, in order to make a comparison of the results between $1 \mathrm{D}$ and $2 \mathrm{D}$.

The distribution of the peak acceleration from observation point $\mathrm{C}$ to point $\mathrm{D}$, with different loess thickness, is analyzed and compared with the results of loess amplification effect mentioned above, which is shown in Figure 8. It can clearly be seen that the characteristics of the amplification of the peak acceleration applying the different method are 


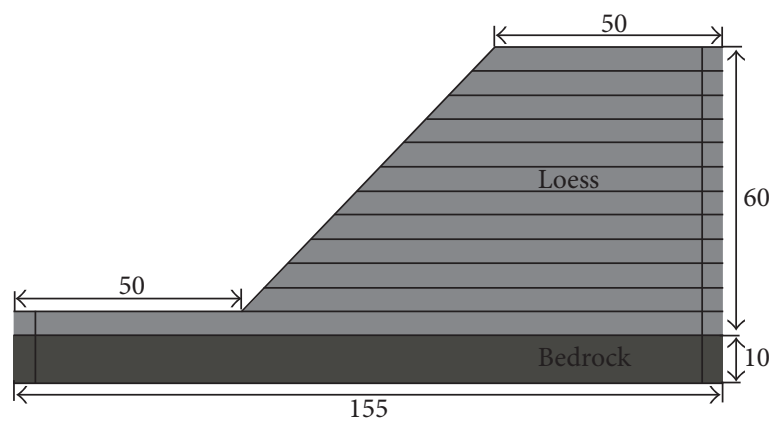

(a)

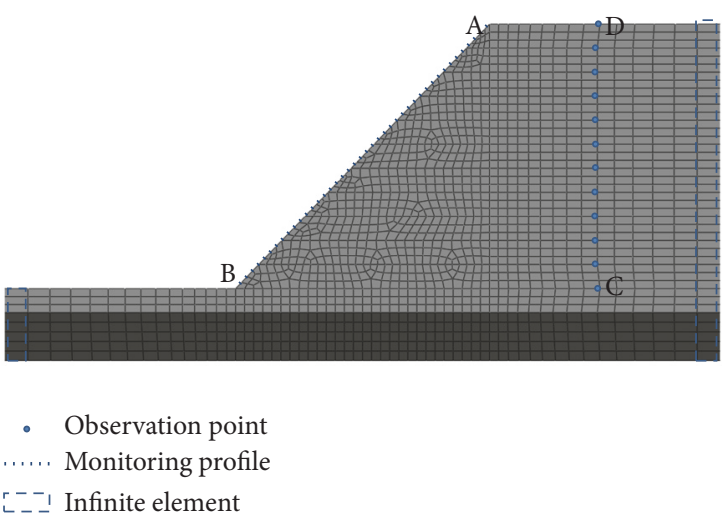

(b)

Figure 7: Models of finite element analysis. (a) Profile of the loess slope (unit: m); (b) Finite element model.

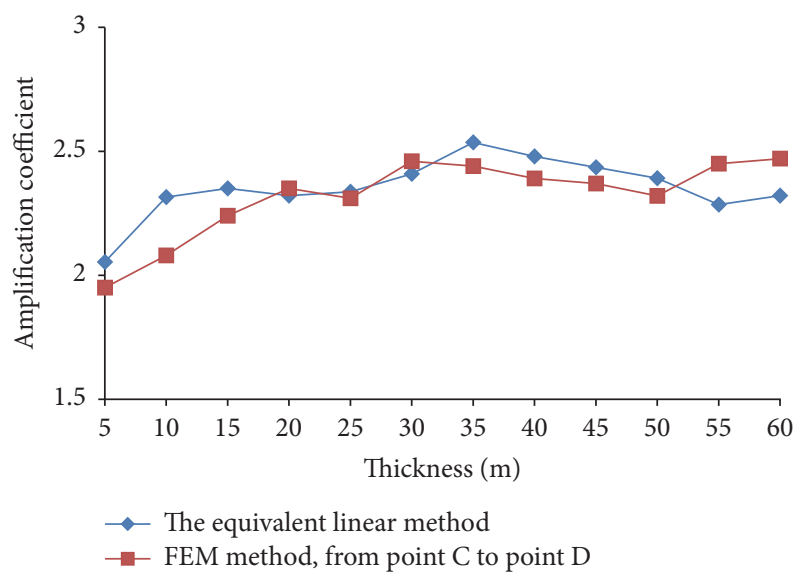

FIGURE 8: The distribution of the amplification coefficient applying different method.

basically coincident. In general, the results reflected that the amplification coefficient increased with increasing depth.

And on this basis the amplification of the acceleration along the free face of loess slope was studied as well. The acceleration time histories of different feature points which are located at the top of the slope and at the slope toe were extracted, respectively. In Figure 9, it is depicted that the peak acceleration of the position at the top of the slope can reach $414 \mathrm{~cm} \cdot \mathrm{s}^{-2}$, while the peak acceleration of the position at the slope toe reaches $313 \mathrm{~cm} \cdot \mathrm{s}^{-2}$. Moreover, the amplification coefficient at different positions of the monitoring profile $\mathrm{AB}$ along the free face was obtained, which is compared with the amplification coefficient of different observation points from C to D (Figure 10). As shown in Figure 10, the amplification coefficients at different positions along the free face show a significant increase of $9.5 \%$. The comparing result reflects the obvious slope effect on seismic acceleration.

5.3. Displacement Analysis of Loess Slope. Figure 11 illustrates the time-horizontal displacement curves of different observation points $A$ and $B$ in the model, located at the top of

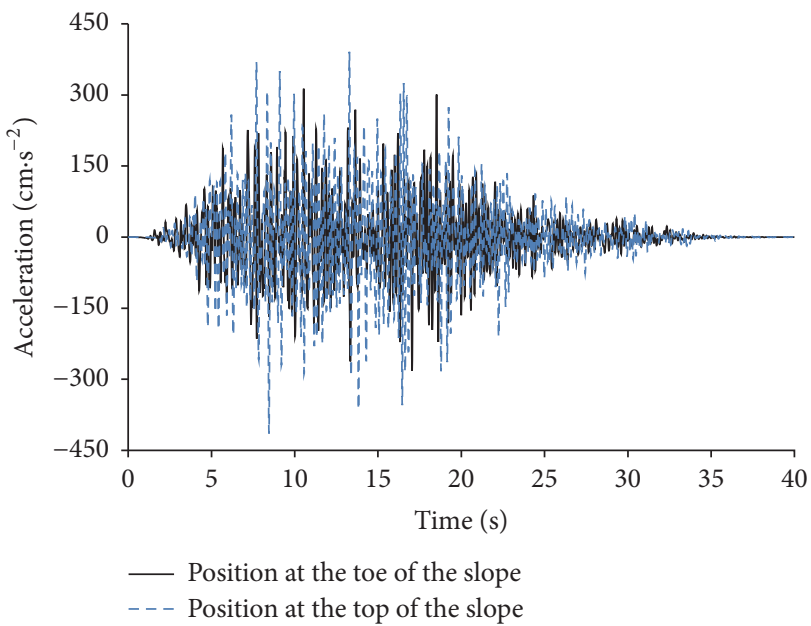

FIgURE 9: The comparison of acceleration time histories at different positions.

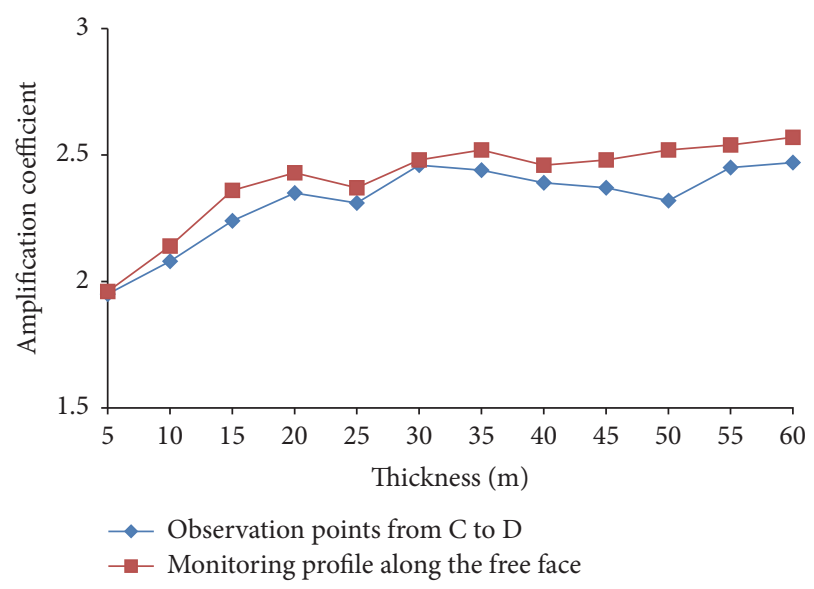

FIgURE 10: The comparison of amplification coefficient.

the slope and at the slope toe, respectively. The displacement increased nonlinearly as the increase of the earthquake 


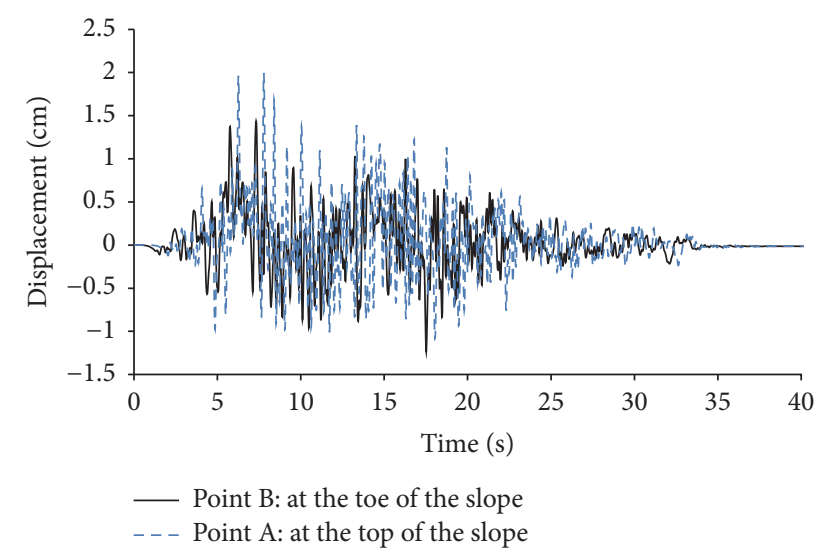

FIgURE 11: The comparing of the horizontal displacement curve of different observation points.

duration time, presenting a maximum displacement at the time when the peak acceleration appeared. As observed in Figure 11, the horizontal displacement of the point $\mathrm{A}$ at the top of the slope is greater than point $B$ at the toe of loess slope. the maximum deformation of point $\mathrm{A}$ reaches 2.0 centimeters, while the value of point $B$ is only 1.5 centimeters. The increased amplitude of the displacement at the top of the slope is about $33 \%$, compared with the value at the toe of loess slope. It can be considered that the cracks or even the collapse occurred under the seismic load because of the difference in deformation.

\section{Conclusion}

In this work, the dynamic response of natural loess field under the effect of earthquake load was studied applying the equivalent linear method. Moreover, a FEM model of typical slope was developed and subsequently used to check the dynamic response of side slope. The following conclusions can be drawn from the results of this study:

(1) The dynamic response of the sites with different loess thickness reflected obvious amplification effect. As the thickness increased, the amplification coefficient had an increasing tendency. Therefore, the nonlinear characteristics of the amplification effect could be observed as well.

(2) The characteristic period of the seismic response spectrum gradually increased with the increase of the soil layer depth, and the variation law of the characteristic periods with the loess thickness presented the logarithmic variation characteristics.

(3) The characteristics of the amplification of the peak acceleration applying the different method were basically coincident, reflecting the fact that the amplification coefficient increased with increasing depth and the obvious loess slope effect under seismic loading.

(4) If the conditions of loess sites are much more complex, one-dimensional calculation results can not reflect the influence of topography, and two- or threedimensional analyses should be taken into account.

\section{Conflicts of Interest}

The authors declare that they have no conflicts of interest.

\section{Acknowledgments}

This project is financially supported by the Fundamental Research Funds for the Central Universities (Grant no. 2015QNB17).

\section{References}

[1] T. S. Liu, Loess and the Environment, China Ocean Press, Beijing, China, 1985.

[2] L. M. Wang, Loess Dynamics, Seismological Press, Beijing, China, 2003.

[3] C. Qiang-guo, "Soil erosion and management on the Loess Plateau," Journal of Geographical Sciences, vol. 11, no. 1, pp. 5370, 2001.

[4] L.-M. Wang, Z.-J. Wu, and K. Xia, "Effects of site conditions on earthquake ground motion and their applications in seismic design in loess region," Journal of Mountain Science, vol. 14, no. 6, pp. 1185-1193, 2017.

[5] L. Xu, H. Yu, W. Cao, and L. Xie, "Site dependence of far-source ground motions during the Wenchuan earthquake," Earthquake Science, vol. 22, no. 5, pp. 531-537, 2009.

[6] L. M. Wang and Z. J. Wu, "Earthquake damage characteristics of the MinXian ZhangXian Ms6.6 earthquake and its lessons," China Earthquake Engineering Journal, vol. 35, no. 3, pp. 401412, 2013.

[7] E. Cruz, R. Riddell, and S. Midorikawa, "A study of site amplification effects on ground motions in Santiago, Chile," Tectonophysics, vol. 218, no. 1-3, pp. 273-280, 1993.

[8] D. Kumar, V. S. Ram, and K. N. Khattri, "A study of source parameters, site amplification functions and average effective shear wave quality factor Qseff from analysis of accelerograms of the 1999 Chamoli earthquake, Himalaya," Pure and Applied Geophysics, vol. 163, no. 7, pp. 1369-1398, 2006.

[9] B. Hassani, H. Zafarani, J. Farjoodi, and A. Ansari, "Estimation of site amplification, attenuation and source spectra of Swaves in the East-Central Iran," Soil Dynamics and Earthquake Engineering, vol. 31, no. 10, pp. 1397-1413, 2011.

[10] S. M. T. Qadri, B. Nawaz, S. H. Sajjad, and R. A. Sheikh, "Ambient noise $\mathrm{H} / \mathrm{V}$ spectral ratio in site effects estimation in Fateh jang area, Pakistan," Earthquake Science, vol. 28, no. 1, pp. 87-95, 2015.

[11] Y. C. Shi, L. M. Wang, and Y. Zhang, "Effects of overburden thickness and topography of loessial sites on earthquake ground motion," Northwestern Seismological Journal, vol. 21, no. 3, pp. 203-206, 1999.

[12] Z.-J. Wu, L.-M. Wang, T. Chen, and P. Wang, "Study of mechanism of site amplification effects on ground motion in far field loess during Wenchuan Ms8.0 earthquake," Rock and Soil Mechanics, vol. 33, no. 12, pp. 3736-3740, 2012.

[13] T. Chen, Z. J. Wu, W. Ma, and L. M. Wang, "Study on the effects of site conditions on earthquake ground motion in loess sites," Chinese Journal of Underground Space and Engineering, vol. 8, no. 5, pp. 969-974, 2012. 
[14] Y. C. Shi, H. W. Cai, and C. S. Sun, "Characteristics of earthquake ground motion parameters in loess areas," Northwestern Seismological Journal, vol. 20, no. 3, pp. 66-72, 1998.

[15] G. D. Xu, P. J. Shi, and X. Y. Zhou, "Artificial ground motion based on target power spectra and envelope," Journal of Earthquake Engineering and Engineering Vibration, vol. 30, no. 2, pp. $1-9,2010$.

[16] X. J. Li, The Soil Seismic Response of One-Dimensional Linear Calculation Program[C]// Seismic Microzonation (Theory and Pratice), Earthquake Publishing House, Beijing, China, 1989.

[17] A.-L. Che, T. Iwatate, and X.-R. Ge, "Dynamic behaviors of subway structure subjected to strong earthquake motions using shaking table tests and dynamic analyses," Rock and Soil Mechanics, vol. 27, no. 8, pp. 1293-1298, 2006.

[18] Z.-J. Wang, Y.-S. Luo, R.-R. Wang, L.-G. Yang, and D.-Y. Tan, "Experimental study on dynamic shear modulus and damping ratio of undisturbed loess in different regions," Chinese Journal of Geotechnical Engineering, vol. 32, no. 9, pp. 1464-1469, 2010. 


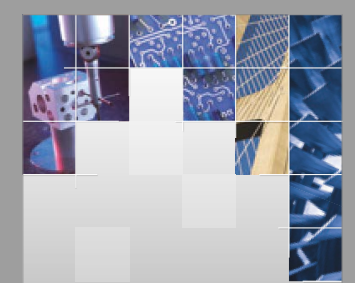

\section{Enfincering}
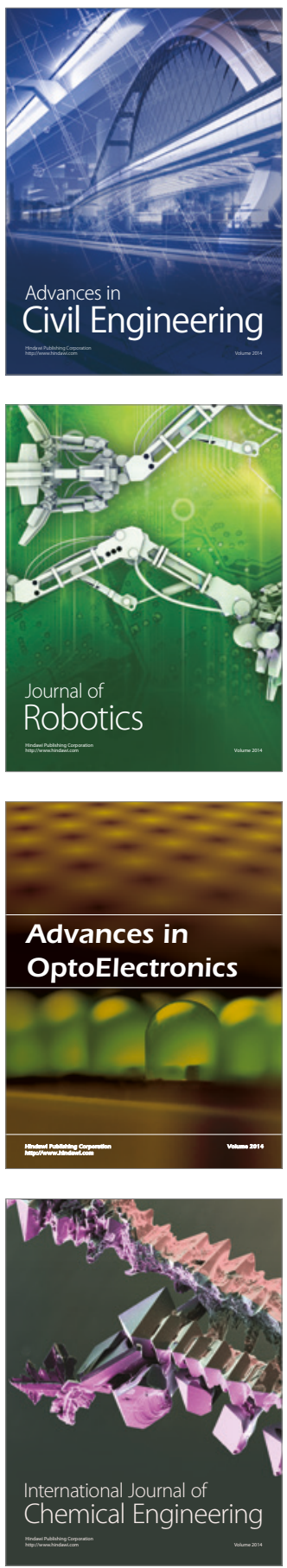

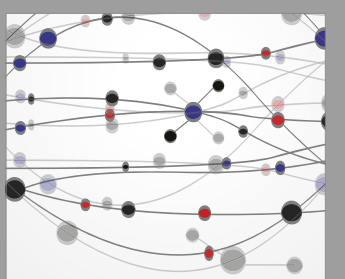

The Scientific World Journal

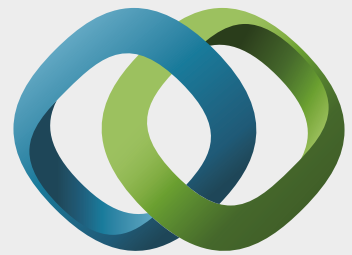

\section{Hindawi}

Submit your manuscripts at

https://www.hindawi.com
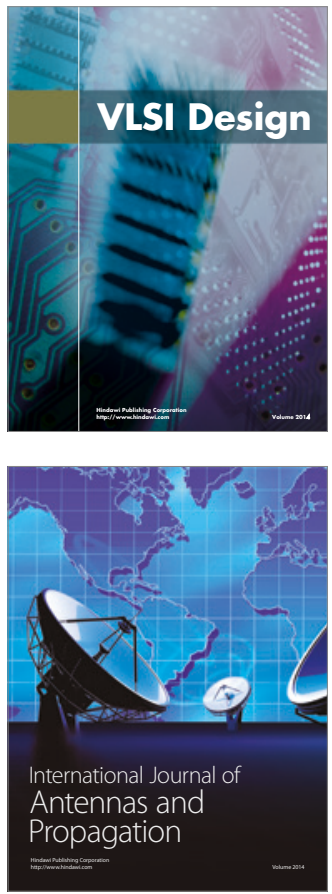

\section{Rotating}

Machinery
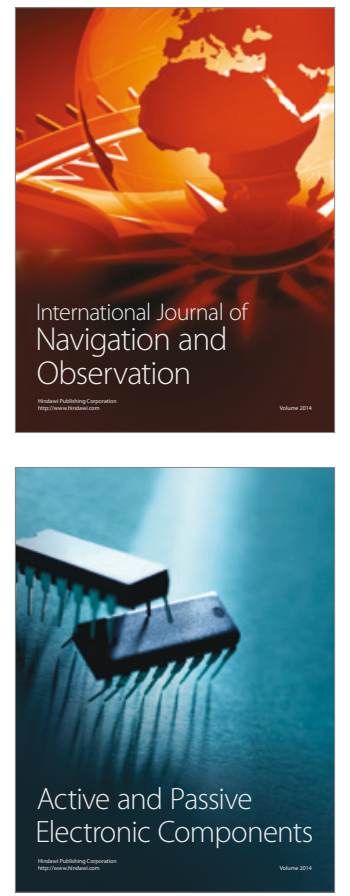
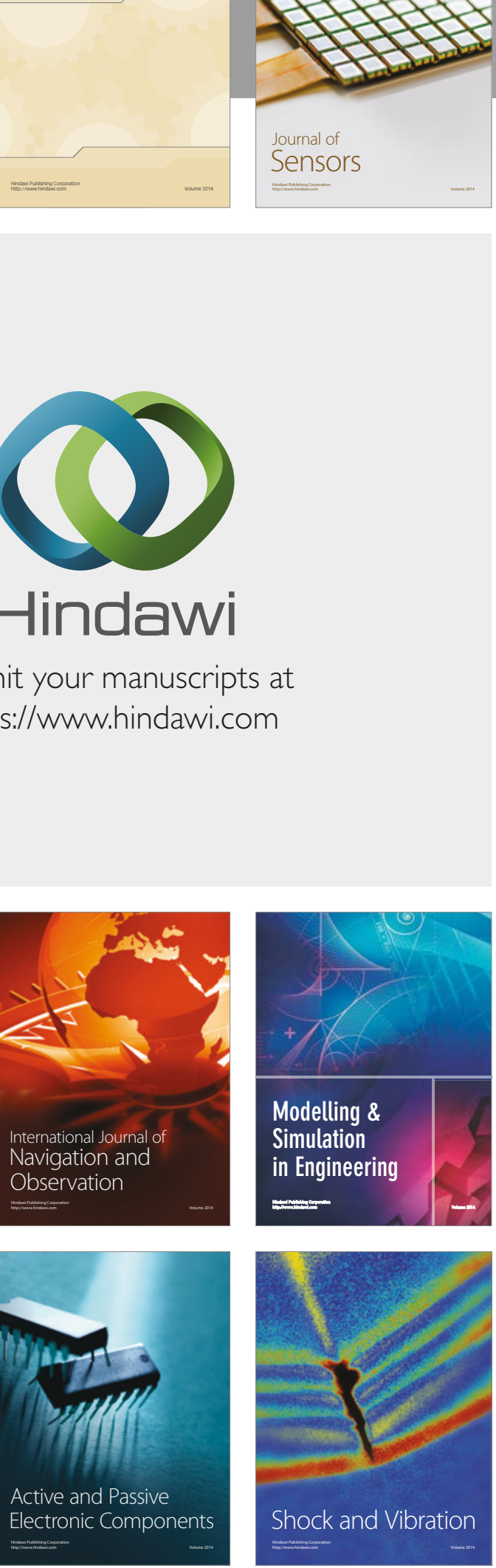
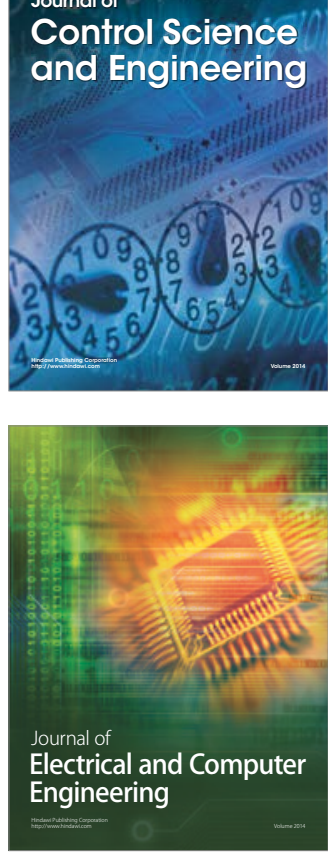

Distributed

Journal of

Control Science

and Engineering
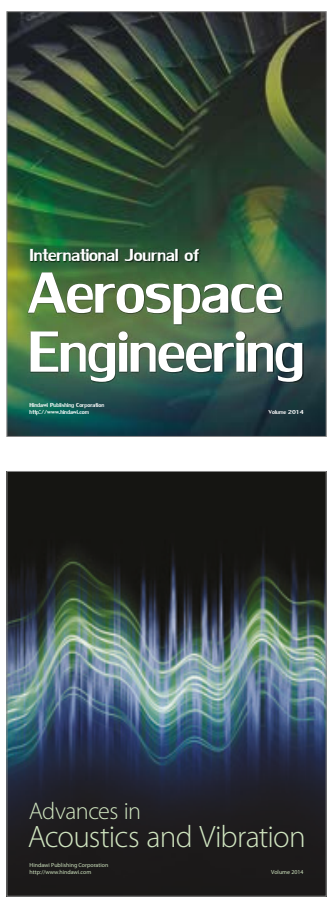

Sensor Networks 